\title{
Alkaline Diuresis as Treatment for 2,4-D Dimethylamine Herbicide Intoxication
}

\author{
Apolonia Berenika Badu, Ade Ajeng Cempakadewi, Brigitta Marcia Budihardja, Anselmus Ake \\ Bajawa Regional General Hospital, Ngada, East Nusa Tenggara, Indonesia
}

Received: $13 / 12 / 2021$

Accepted: $14 / 12 / 2021$

Published: 19/01/2022

How to cite this article: Badu AB, Cempakadewi AA, Budihardja BM Ake A. Alkaline diuresis as treatment for 2,4D dimethylamine herbicide intoxication. EJCRIM 2022;9: doi:10.12890/2022_003126.

Conflicts of Interests: The authors declare there are no competing interests.

Acknowledgements: We would like to thank the patient and her family who gave written informed consent for the publications of these case details. The e-poster version of this case report was presented at and won first place in Pertemuan IImiah Tahunan Interna 2021 (Internal Medicine Annual Scientific Meeting) held by Faculty of Medicine of the University of Indonesia in August 2021.

This article is licensed under a Commons Attribution Non-Commercial 4.0 License

\section{ABSTRACT}

Acute intoxication with 2,4-D dimethylamine is rare, often fatal and can cause signs and symptoms in different organ systems. This case report describes the effectiveness of alkaline diuresis as a life-saving treatment for chlorophenoxy intoxication, especially in healthcare facilities without access to haemodialysis. A patient had attempted suicide by ingesting 2,4-D dimethylamine, with toxic effects on the central and peripheral nervous systems, and the gastrointestinal and respiratory systems. However, she significantly improved after alkaline diuresis, accompanied by resuscitation, decontamination of the gastrointestinal system, and supportive therapies.

\section{LEARNING POINTS}

- With no known of antidote, 2,4-D dimethylamine intoxication can be fatal if not treated promptly.

- Alkaline diuresis can be a life-saving treatment, especially in rural area with no access to haemodialysis.

- Treatment with alkaline diuresis can give a good result in patients who present with severe intoxication.

\section{KEYWORDS}

Herbicide intoxication, 2,4-D dimethylamine, alkaline diuresis, chlorophenoxy

\section{INTRODUCTION}

The use of 2,4-D dimethylamine is becoming more common due to increasing resistance to the herbicides glyphosate and paraquat ${ }^{[1]}$. Therefore, growth in the number of cases of 2,4-D dimethylamine intoxication should be anticipated. This herbicide shows a variety of dose-dependent toxicity mechanisms, including cell membrane damage, uncoupling of oxidative phosphorylation, and disruption of acetyl coenzyme A metabolism ${ }^{[2]}$. Toxic effects may involve the nervous system, heart, lungs, liver, kidney, muscles and endocrine system ${ }^{[3]}$. In many cases, the results are fatal ${ }^{[2,4]}$. This report describes the effectiveness of alkaline diuresis as a life-saving treatment for 2,4-D dimethylamine intoxication with severe symptoms in a rural area.

\section{CASE DESCRIPTION}

A 19-year-old woman attended the public health centre with vomiting, abdominal pain, malaise, and a burning sensation in her chest. She had deliberately drunk $65 \mathrm{ml}$ of DMA 6 solution containing the active ingredient 2,4-D dimethylamine $825 \mathrm{~g} / \mathrm{l}$. She was fully conscious and received normal saline and activated charcoal. However, 15 minutes later, she rapidly lost consciousness and was immediately referred to hospital. 
On admission, she presented with a Glasgow Coma Scale of E2M4V2. Blood pressure was 100/70 mmHg, pulse 105 beats per minute, respiratory rate $32-36$ times per minute, temperature $37.5^{\circ} \mathrm{C}$, and oxygen saturation $96-98 \%$ with oxygenation 4 litres per minute. Muscle tone was decreased and tendon reflexes were absent. Routine blood tests showed leucocytosis with absolute neutrophilia. Blood gas analysis revealed partially compensated respiratory alkalosis, while routine urine examination revealed haematuria. The patient was diagnosed with herbicide intoxication with loss of consciousness, sepsis and septic shock, stress ulcers, transaminitis, and attempted suicide. She was treated in the intensive care unit with oxygenation, intravenous fluids with normal saline, cefotaxime, omeprazole and ondansetron. Gastric lavage was performed. Initially, the liquid was blackish-brown in colour, but after the administration of $200 \mathrm{ml}$ of fluid, the liquid became clear. Antacids and sucralfate were given to treat stress ulcers.

Over the next 7 hours, the patient's condition deteriorated. She became unresponsive to painful stimuli, her blood pressure decreased to $80 / 50 \mathrm{mmHg}$, and blood clots were found in the nasogastric tube. Fluid resuscitation was given immediately with $1500 \mathrm{ml}$ normal saline, but blood pressure did not reach the target. The patient was given a vasopressor and reached the systole target pressure of $>100 \mathrm{mmHg}$. Omeprazole was given in a loading dose, then continued with maintenance infusion. Tranexamic acid was also given.

By the second day, the patient's temperature had reached $38.6^{\circ} \mathrm{C}$ and paracetamol was given. Alkaline diuresis was initiated by giving 1 $\mathrm{mEq} / \mathrm{kg}$ sodium bicarbonate in $0.9 \%$ normal saline $100 \mathrm{ml}$ intravenously within 30 minutes, and then supplemented with $75 \mathrm{mEq}$ of sodium bicarbonate and $25 \mathrm{mEq}$ of potassium in $500 \mathrm{ml}$ of $5 \%$ dextrose within 8 hours. Furosemide 20 mg was given every 12 hours intravenously for 8 days, with gradual dose reduction starting from the fifth day. Furosemide was then continued orally. Intravenous dexamethasone is also given to treat cerebral oedema.

On the fourth day, the patient's leukocyte count began to decrease, but liver enzyme levels were increased. She started responding to treatment and became fully conscious after 5 days and began accepting oral therapy. She was transferred to a regular ward on the tenth day and discharged on the twelfth day in a stable condition (Fig. 1).

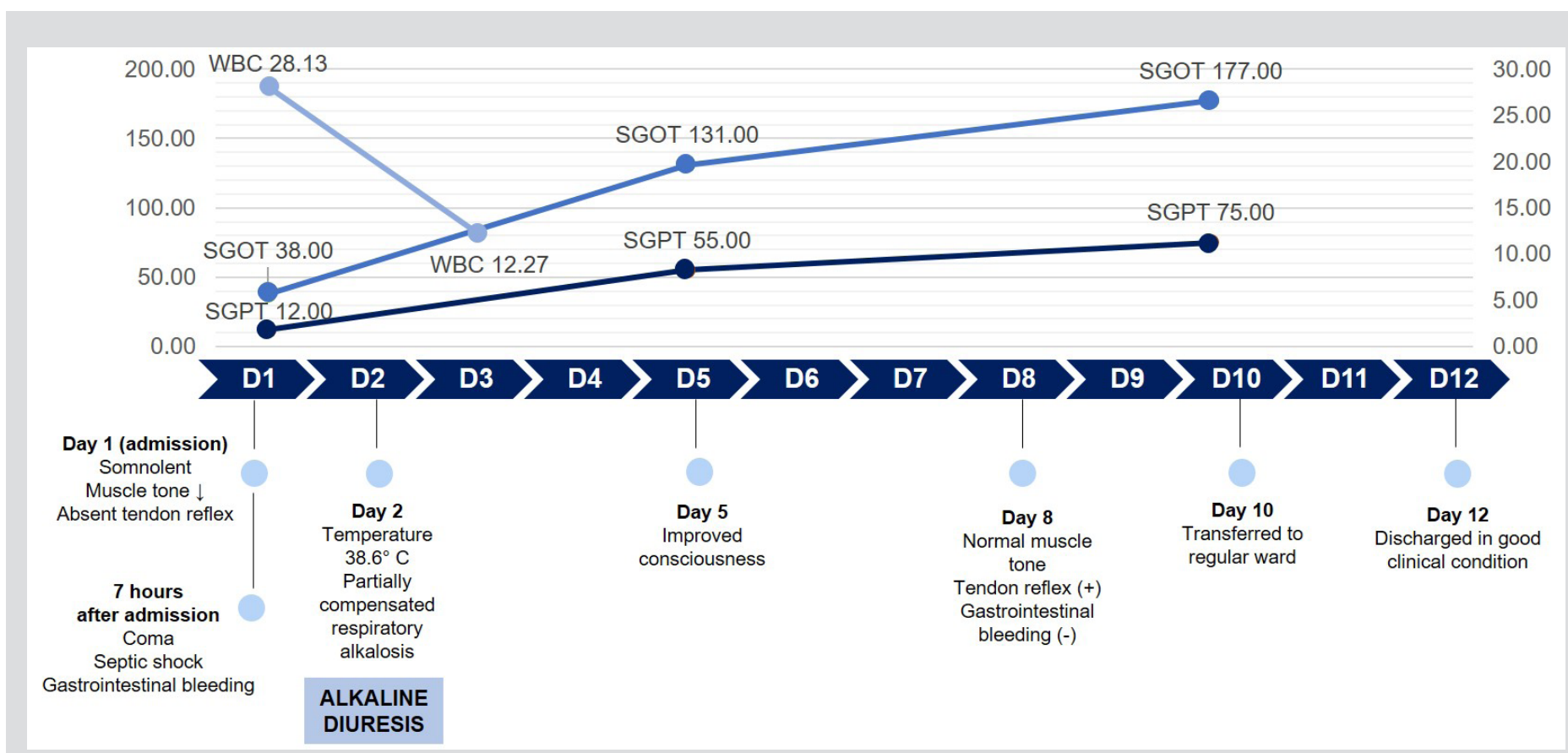

Figure 1. Timeline of clinical condition

\section{DISCUSSION}

The patient was diagnosed immediately based on her history; early identification of the causative agent early is very useful in management. The amount of herbicide consumed was quite large $(65 \mathrm{ml})$ since this was an attempt at suicide. In this case, a toxic effect was seen in multiple organ systems, including the gastrointestinal, respiratory and nervous systems. Septic shock was also found as demonstrated by symptoms, physical examination and laboratory results. 
Until now, there has been no specific antidote for 2,4-D dimethylamine intoxication. Chlorophenoxy is a weak acid (pKa 2.6 for 2,4-D) that is excreted in the urine in the same form. Intravenous sodium bicarbonate acts by increasing urine $\mathrm{pH}$. Renal excretion is better in alkaline urine conditions $\left(63 \mathrm{ml} / \mathrm{min}\right.$ at $\mathrm{pH}$ 8.3) than in acidic conditions $(0.14 \mathrm{ml} / \mathrm{min} \text { at } \mathrm{pH} 5.1)^{[2]}$. For each unit increase in urine $\mathrm{pH}$, the clearance of 2,4-D by the kidney is estimated to increase nearly five-fold ${ }^{[3]}$. Therefore, the administration of sodium bicarbonate with a target urine flow of 4-6 ml/minute will increase the excretion of 2,4-D dimethylamine. In this case, urine $\mathrm{pH}$ after alkaline diuresis was not evaluated, so the renal clearance and half time of 2,4-D in this patient could not be determined. According to the literature, hypokalaemia may occur during alkaline diuresis and so sodium bicarbonate should be accompanied by potassium administration ${ }^{[2]}$.

Haemodialysis is more efficient than alkaline diuresis and can induce the release of toxic substances without manipulating urine $\mathrm{pH}$ and the requirement for large amounts of intravenous fluids. However, the treatment plan adopted is ultimately based on the availability of facilities. In addition to haemodialysis, there are case reports describing plasmapheresis as a therapy for intoxication, but there is limited evidence to support this approach in the treatment of severe 2,4-D dimethylamine intoxication ${ }^{[3,4]}$.

In cases of mild intoxication, supportive therapy might be sufficient, but, in cases of severe intoxication, treatment with alkaline diuresis or haemodialysis is required ${ }^{[4]}$. However, there is no severity classification as a reference to determine the most appropriate therapy.

Shock and loss of consciousness in cases of 2,4-D dimethylamine intoxication indicate a poor prognosis. However, timely administration of an alkaline diuresis can be life-saving. Recovery can be achieved in weeks to months despite initial severe toxicity ${ }^{[2,4]}$.

\section{CONCLUSION}

2,4-D dimethylamine intoxication is rare, does not have an antidote, and has high morbidity and mortality. Alkaline diuresis as a life-saving treatment must be accompanied by other therapies including initial emergency resuscitation, decontamination of the gastrointestinal system, and supportive treatment.

\section{REFERENCES}

1. Genetic Literacy Project. Herbicide-resistant crops can exacerbate 'superweeds' but new GMversions can help control problem. Available from: https://geneticliteracyproject. org/2014/06/27/herbicide-resistant-crops-can-exacerbate-superweeds-but-new-gm-versions-and-judicious-use-can-control-problem/ (accessed 15 Sep 2021).

2. Hiran S, Kumar S. 2, 4-D dichlorophenoxyacetic acid poisoning; case report and literature review. Asia Pacific J Med Toxicol 2017;6(1):29-33.

3. Bradberry SM, Watt BE, Proudfoot AT, Vale JA. Mechanisms of toxicity, clinical features, and management of acute chlorophenoxy herbicide poisoning: a review. $J$ Toxicol Clin Toxicol 2000;38(2):111-22.

4. Bradberry SM, Proudfoot AT, Vale JA. Poisoning due to chlorophenoxy herbicides. Toxicol Rev 2004;23(2):65-73. 